\title{
Envy, leisure, and restrictions on working hours
}

\author{
Francisco Alvarez-Cuadrado* \\ Department of Economics \\ McGill University \\ 855 Sherbrooke Street West \\ Montreal, QC, Canada H3A 2T7
}

July 2006

\begin{abstract}
We present a simple model of capital accumulation where agents care about their consumption relative to the consumption of other members of society. This concern with "envy" captures the intuition behind the growing body of empirical evidence that places interpersonal comparisons as a key determinant of well-being. In this context we quantify the extent of the distortions and welfare costs associated with envy. Under conservative estimates of envy we find that the implied welfare losses are substantial. Our analysis explores the implications of alternative policy arrangements designed to minimize the effects of the consumption externality. Our results suggest that if the optimal tax policy is not politically feasible restrictions on working hours provide an alternative tool to induce a market outcome that resembles the efficient allocation achieved under a benevolent central planner.
\end{abstract}

JEL classification: D62, H21, H23, J22

Keywords: Consumption externalities, working hours, welfare evaluation.

\footnotetext{
* I gratefully acknowledge the constructive suggestions of Leah Brooks, Benjamin Dennis, John Galbraith, Jenny Hunt, Ngo Van Long and Chris Ragan, as usual all remaining errors are my own. Tel.: 1514398 6762; Fax: 1514 398 4938; E-mail address: francisco.alvarez-cuadrado@mcgill.ca
} 


\section{Introduction}

The assumption that preferences are independent across households is standard in the economic literature, although it is not particularly appealing. Indeed, social scientists have long stressed the relevance of status seeking as being an important characteristic of human behavior (see Aristotle (1941), Kant (1797), Schoeck (1966), Rawls (1971)). In our discipline, the idea that the overall level of satisfaction derived from a given level of consumption depends, not only on the consumption level itself, but also on how it compares to the consumption of other members of society, is not new. Though origins of this proposition can be traced as far back as Smith (1759) and Veblen (1899), it was not until the work of Duesenberry (1949) and Pollak (1976) that an effort was made to provide this idea with some micro-theoretic foundations. The subsequent literature has often referred to this type of interdependence as "catching up with the Joneses” as in Abel (1990), “keeping up with the Joneses” as in Gali (1994), “status” as in Fisher and Hoff (2000), “jealousy” as in Dupor and Liu (2003), or “envy” as in Eaton and Eswaran (2003).

A growing body of empirical evidence has confirmed the importance of preference interdependence. Clark and Oswald (1996), using a sample of 5,000 British workers, find that workers' reported satisfaction levels are inversely related to their comparison wage rates emphasizing the role of positional externalities. Neumark and Postlewaite (1998) propose a model of relative income to rationalize the striking rise in the employment of married women in the U.S. during the past century. Using a sample of married sisters, they find that married women are 16 to 25 percent more likely to work outside the home if their sisters' husbands earn more than their own husbands. Luttmer (2005) matches individual-level panel data on well-being from the U.S. National Survey of Families and Households to census data on local average earnings. 
After controlling for income and other own characteristics, he finds that local average earnings have a significantly negative effect on self-reported happiness. Furthermore, his results highlight that the negative effect of neighbors' earnings is significantly stronger for those who socialize frequently with neighbors but not for those who socialize more frequently with relatives, friends outside the neighborhood or colleagues ${ }^{1}$.

Frank (1985) stresses the conflict that arises between individual and social welfare in the presence of such consumption externalities. It is well known that envy creates a gap between the social and private benefits from consumption, increasing the relative appeal of consumption over leisure. As a result, envious households consume and work above the welfare-maximizing levels, providing a basis for welfare-improving government interventions. In general, any policy that increases the price of consumption relative to leisure, a tax on consumption or a subsidy to leisure, will move the competitive equilibrium closer to the efficient allocation of resources.

This paper develops a model, consistent with cross-country and time series variation in hours worked for the G-7 countries, to quantify the distortions introduced by envy in the equilibrium allocation of resources. We use this framework to explore the welfare properties of alternative policy arrangements designed to minimize these distortions.

Under conservative estimates of envy we find that the welfare gain associated with the optimal fiscal policy is equivalent to a permanent increase in consumption, today and in all future periods, close to one fourth of the laissez faire level of consumption. Even when we incorporate information about the current levels of taxation for the G-7 economies, we still find

\footnotetext{
${ }^{1}$ Beyond these studies, status concerns have been introduced to account for observed departures from the neoclassical paradigm in the asset pricing literature (Abel (1990), Gali (1994) and Campbell and Cochrane (1999)), the literature on labor market outcomes (Akerlof and Yellen (1990), the consumption literature (Van de Stadt et al. (1985), Kapteyn et al. (1997), Ravina (2005), Alvarez-Cuadrado and Sutthiphisal (2006)), the experimental literature (Solnick and Hemenway (1998), Johansson-Stenman et al. (2002) and Alpizar et al. (2005)) and the real business cycle literature (Ravn et al. (2006)).
} 
important welfare gains in terms of permanent consumption increases that range from $4.5 \%$ of consumption for the U.S. and Japan down to 1\% for France and Germany. More surprisingly, the welfare gains associated with limitations on working time are almost as large as the gains derived from the optimal fiscal policy. Regulations that impose restrictions on working hours, legally mandated vacations or workweek limitations, might serve as a coordination device that minimizes the negative effect of envy in the competitive choice of working hours. In view of these results we conclude that, in circumstances where the optimal fiscal policy is difficult to implement, restrictions on working time provide an alternative tool to achieve a market outcome close to the efficient allocation. We speculate that such a consideration might provide a new rationale for the widespread use of work-time restrictions in develped economies.

Fischer and Hof (2000), Alvarez-Cuadrado et al. (2005), Alonso-Carrera et al. (2006), Liu and Turnovsky (2005) and Turnovsky and Monteiro (2006) explore a theoretical framework similar to ours. Their focus is on the qualitative characterization of the optimal tax policy while our emphasis is on the quantification of the distortions and welfare costs associated with envy and the evaluation of alternative policy actions. Our welfare results are closely related to the recent literature that explores the determinants of (self-reported) well-being such as Easterlin (1995), Frey and Stutzer (2002), Helliwell (2003) and Layard (2005). This literature highlights the importance of interpersonal comparisons as a key determinant of self-reported happiness. Finally, our evaluation of the effects of working time limitations is consistent with the negative relationship between hours worked and life satisfaction that Alesina et al. (2005) find across European countries.

The paper is organized as follows. Section 2 sets out the basic model and compares the decentralized and centrally planned solutions. Section 3 quantifies the consequences of 
comparative consumption in the equilibrium allocation of resources and characterizes the optimal fiscal policy. Section 4 contrast the implications of our model with G-7 countries' data on working hours and Section 5 evaluates the consequences of limitations imposed on working hours. The conclusions are summarized in Section 6, while the Appendices provide some technical details.

\section{The Model}

Consider an economy populated by $N$ identical and infinitely lived households. Population grows at the exogenous rate $\dot{N} / N=n$. The $i$-th agent is endowed with a unit of time that can be enjoyed in the form of leisure, $l_{i}$, or devoted to work, $L_{i} \equiv 1-l_{i}$. At any point in time, households derive utility from their leisure time, their current level of consumption, $C_{i}$, and the comparison of their consumption to the economy-wide average level of consumption, $\bar{C} \equiv \sum_{i=1}^{N} C_{i} / N$. Following Abel (1990), Carroll et al. (1997) and Alonso-Carrera et al. (2005, 2006) we adopt the following iso-elastic specification:

$$
\begin{aligned}
& U\left(C_{i}, \bar{C}, l_{i}\right) \equiv \frac{1}{1-\varepsilon}\left[C_{i} \bar{C}^{-\gamma} l_{i}^{\theta}\right]^{1-\varepsilon}=\frac{1}{1-\varepsilon}\left[C_{i}^{(1-\gamma)}\left(\frac{C_{i}}{\bar{C}}\right)^{\gamma} l_{i}^{\theta}\right]^{1-\varepsilon} \\
& 0<\gamma<1, \varepsilon>1, \theta>0
\end{aligned}
$$

This specification captures the intuition that lies behind the growing body of empirical evidence that places interpersonal comparisons as a key determinant of individual well-being. As we can see from the second expression in (1), agents derive utility from a geometric weighted average of absolute and relative consumption. The restrictions imposed on the consumption 
externality parameter, $\gamma$, guarantee that agents are in fact envious and that a proportional increase in individual and average consumption increases utility ${ }^{2}$.

Individual output, $Y_{i}$, is produced combining the agent's capital stock, $K_{i}$, her labor, $1-l_{i}$, and the publicly available level of technology, assumed to grow at the exogenous constant rate $\dot{A} / A=g$, according to the Cobb-Douglas technology,

$$
Y_{i}=\alpha\left(A\left(1-l_{i}\right)\right)^{\sigma} K_{i}^{(1-\sigma)} \quad 0<\sigma<1
$$

The technology exhibits diminishing marginal product to each private factor and constant returns to scale in the two factors, capital and labor in efficiency units.

\subsection{Competitive Solution}

The agent's objective is to maximize the present value of (1), discounted using the rate of time preference, $\beta$, subject to her capital accumulation equation,

$$
\dot{K}_{i}=\left(1-\tau_{k}\right) r K_{i}+\left(1-\tau_{w}\right) w\left(1-l_{i}\right)-\left(1+\tau_{c}\right) C_{i}-(n+\delta) K_{i}+T_{i}
$$

where $r$ is the gross return on capital, $w$ is the wage rate, $\tau_{k}, \tau_{w}$ and $\tau_{c}$ are taxes on capital income, labor income and consumption, respectively, and $T_{i}$ is a per capita lump-sum transfer. We assume that capital depreciates at the exponential rate $\delta$.

Since agents are atomistic, they ignore the effects of their individual consumption and leisure choices on the evolution of aggregate consumption, capital and labor supply, taking prices and average consumption as given. Performing the optimization, we reach the following first order conditions, where $\lambda_{i}$ is the co-state variable associated with the individual's capital

\footnotetext{
2 The central planner acknowledges the effects of individual consumption choices on average consumption internalizing the external effect. Under those circumstances the utility function is not jointly concave in both $C_{i}$ and $\bar{C}$ and the first-order conditions may not yield a maximum. In this case Alonso-Carrera et al. (2005) argues that the interior solution will ensure utility maximization if one restricts $\varepsilon>1$. This restriction is consistent with the available empirical evidence and therefore we impose it.
} 
stock and the superscript " $d$ " denotes decentralized choices,

$$
\begin{aligned}
& \left(C_{i}^{d}\right)^{-\varepsilon}\left(\bar{C}^{d}\right)^{-\gamma(1-\varepsilon)}\left(l_{i}^{d}\right)^{\theta(1-\varepsilon)}=\lambda_{i}^{d}\left(1+\tau_{c}\right) \\
& \theta\left(C_{i}^{d}\right)^{1-\varepsilon}\left(\bar{C}^{d}\right)^{-\gamma(1-\varepsilon)}\left(l_{i}^{d}\right)^{\theta(1-\varepsilon)-1}=\lambda_{i}^{d} w^{d}\left(1-\tau_{w}\right) \\
& \left(1-\tau_{k}\right) r^{d}-\delta-n=\beta-\dot{\lambda}_{i}^{d} / \lambda_{i}^{d}
\end{aligned}
$$

Equation (4a) equates the utility of an additional unit of consumption to the tax-adjusted shadow value of capital. Equation (4b) equates the marginal utility of leisure to its opportunity cost in terms of consumption, the after-tax wage, valued at the shadow value of capital. Equation (4c) is the standard intertemporal allocation condition equating the after-tax marginal return to capital to the rate of return on consumption. Finally, in order to ensure that the intertemporal budget constraint is satisfied, the following transversality condition is imposed:

$$
\lim _{t \rightarrow \infty} e^{-\beta t} \lambda_{i}^{d} K_{i}^{d}=0
$$

Combining (4a) and (4b), we obtain the familiar static allocation condition that equates the marginal rate of substitution between consumption and leisure to their after-tax relative price,

$$
\frac{l_{i}^{d}}{\theta C_{i}^{d}}=\frac{1+\tau_{c}}{w^{d}\left(1-\tau_{w}\right)}
$$

As we will see later, this relation is the only channel through which the distortions introduced by envy affect the equilibrium behavior of our economy.

Since all individuals are assumed to be identical, individual consumption and average consumption coincide, and so $\bar{C}^{d}=C_{i}^{d}$. Aggregating across households, the aggregate capital stock becomes $K^{d}=N K_{i}^{d}$ and aggregate output is given by 


$$
Y^{d}=N Y_{i}^{d}=\alpha\left(A N\left(1-l_{i}^{d}\right)\right)^{\sigma}\left(N K_{i}^{d}\right)^{(1-\sigma)}=\alpha\left(A N\left(1-l^{d}\right)\right)^{\sigma}\left(K^{d}\right)^{(1-\sigma)}
$$

The equilibrium returns to capital and labor are given by their respective marginal products evaluated at the aggregate level, according to

$$
r^{d}=(1-\sigma) \frac{Y^{d}}{K^{d}} ; \quad w^{d}=\sigma \frac{Y^{d}}{N\left(1-l^{d}\right)}
$$

Finally, we assume that the government balances the budget every period so that $\tau_{k} r^{d} K^{d}+\tau_{w} w^{d} N+\tau_{c} C^{d}=T^{d}$, where $T^{d}=N T_{i}^{d}$ and $C^{d}=N C_{i}^{d}$ are aggregate transfers and aggregate consumption respectively.

We define a balanced growth path as one along which all variables grow at a constant rate and per capita work effort is constant. Because capital is accumulated from final output, the only balanced solution is one in which the capital-output ratio is constant. With population and technology growing at exogenous rates, it is convenient to define variables expressed in units of effective labor, $k^{d} \equiv K^{d} / A N, c^{d} \equiv C^{d} / A N$ and $y^{d} \equiv Y^{d} / A N$. The equilibrium dynamics of our economy are fully determined by the initial condition $k^{d}(0)=k_{0}$, the transversality condition (4d) and the following pair of differential equations in $k^{d}$ and $l^{d} 3$,

$$
\begin{aligned}
& \dot{k}^{d}=\left(1-\frac{c^{d}}{y^{d}}\right) y^{d}-(\delta+g+n) k^{d} \\
& \dot{l}^{d}=F\left(l^{d}\right)\left[\left(\left(1-\tau_{k}\right)-\eta\left(1-\frac{c^{d}}{y^{d}}\right)\right)(1-\sigma) \frac{y^{d}}{k^{d}}-(\beta+(1-\eta(1-\sigma))(\delta+n)+\eta \sigma g)\right] \\
& \frac{c^{d}}{y^{d}}=\frac{\sigma}{\theta} \frac{l^{d}}{1-l^{d}} \frac{1-\tau_{w}}{1+\tau_{c}}
\end{aligned}
$$

\footnotetext{
${ }^{3}$ See the Appendix for a detailed derivation of the system of differential equations.
} 
$F\left(l^{d}\right) \equiv \frac{l^{d}\left(1-l^{d}\right)}{\eta\left(1-\sigma l^{d}\right)-(1-\varepsilon) \theta\left(1-l^{d}\right)}>0$

where $y^{d}=\alpha\left(1-l^{d}\right)^{\sigma}\left(k^{d}\right)^{1-\sigma}$ is the aggregate production function expressed in units of effective labor, $\eta \equiv \gamma(1-\varepsilon)+\varepsilon$ is a measure of the willingness to shift consumption across time and (7c) is the equilibrium counterpart of (4e). Imposing the steady state condition, $\dot{k}^{d}=\dot{l}^{d}=0$, the previous system can be solved for the equilibrium values of the relevant variables noting that (7a) and (7b) imply the following steady state output-capital ratio and saving rate for the decentralized solution:

$$
\begin{aligned}
& \frac{\tilde{y}^{d}}{\tilde{k}^{d}}=\frac{\beta+\delta+n+\eta g}{\left(1-\tau_{k}\right)(1-\sigma)} \\
& \tilde{s}^{d} \equiv 1-\frac{\tilde{c}^{d}}{\tilde{y}^{d}}=\frac{\left(1-\tau_{k}\right)(1-\sigma)(\delta+g+n)}{\beta+\delta+n+\eta g}
\end{aligned}
$$

Combining (8b) with (7c) we obtain the steady state level of leisure, $\tilde{l}^{d}$, which jointly with (8a) and the production function determines the steady state level of scale adjusted capital $\tilde{k}^{d}$. Finally (7c) determines the steady state level of scale adjusted consumption $\tilde{c}^{d}$.

\subsection{The Planner's Solution.}

In a competitive equilibrium individual agents ignore the effects that their consumption choices have on the utility of other agents. As a consequence, agents' consumption, leisure and capital may diverge from the socially optimal levels that would be chosen by a benevolent central planner. The central planner acknowledges that individual consumption choices create distortions through their effects on average consumption and therefore he perceives the following

utility specification for the $i$-th individual, $U\left(C_{i}, \bar{C}, l_{i}\right)=\frac{1}{1-\varepsilon}\left[C_{i}^{1-\gamma} l_{i}^{\theta}\right]^{1-\varepsilon}$. Setting taxes equal to 
zero, the planner maximizes the present value of his perceived utility subject to (2), (3) and (6).

The optimality conditions are identical to (4), except for (4a) which becomes,

$$
(1-\gamma)\left(C_{i}^{p}\right)^{-\varepsilon-\gamma(1-\varepsilon)}\left(l_{i}^{p}\right)^{\theta(1-\varepsilon)}=\lambda_{i}^{p}
$$

where the superscript " $p$ " denotes the planner's choices. Comparing (9) and (4a), with $\tau_{c}=0$, we see that the distortion introduced by the externality takes the form of an overvaluation, by a factor $1 /(1-\gamma)$, of the marginal utility of consumption.

This overvaluation of consumption distorts the marginal rate of substitution between consumption and leisure. Combining (4a), (4b) and (9) we reach the following relation between the marginal rates of substitution of the decentralized and the centrally planned economies for given levels of consumption and leisure ${ }^{4}$ :

$$
M R S_{c, l}^{d}=\frac{l}{\theta C}>\frac{(1-\gamma) l}{\theta C}=M R S_{c, l}^{p}
$$

Since envious households overvalue consumption, their willingness to substitute from leisure towards consumption is too high relative to the socially desirable level. This distortion leads to a competitive solution characterized by an inefficiently low level of leisure and thus inefficiently high levels of labor supply and consumption.

Following a similar approach as in the decentralized economy, the equilibrium dynamics of the centrally planned solution are characterized by

$$
\dot{k}^{p}=\left(1-\frac{c^{p}}{y^{p}}\right) y^{p}-(\delta+g+n) k^{p}
$$

\footnotetext{
${ }^{4}$ In general, with a composite consumption good and endogenous labor supply, a consumption externality can introduce distortions along two margins: the intertemporal allocation of consumption and the static trade-off between consumption and leisure. As shown by Liu and Turnovsky (2005) and Alonso-Carrera et al. (2006), if preferences are time separable and iso-elastic, the marginal rate of substitution of consumption between two points in time coincides under both competitive and centrally planned solutions. Since iso-elastic preferences are required for the existence of a balanced growth path our model rules out by assumption the the first channel for the externality to have an effect in equilibrium allocations.
} 


$$
\begin{gathered}
i^{p}=F\left(l^{p}\right)\left[\left(1-\eta\left(1-\frac{c^{p}}{y^{p}}\right)\right)(1-\sigma) \frac{y^{p}}{k^{p}}-(\beta+(1-\eta(1-\sigma))(\delta+n)+\eta \sigma g)\right] \\
\frac{c^{p}}{y^{p}}=\frac{(1-\gamma) \sigma}{\theta} \frac{l^{p}}{1-l^{p}} \\
F\left(l^{p}\right) \equiv \frac{l^{p}\left(1-l^{p}\right)}{\eta\left(1-\sigma l^{p}\right)-(1-\varepsilon) \theta\left(1-l^{p}\right)}>0
\end{gathered}
$$

together with the initial condition $k(0)=k_{0}$ and the transversality condition (4d). Imposing the steady state condition $\dot{k}^{p}=\dot{l}^{p}=0$, the equilibrium output-capital ratio and the saving rate are again given by (8a) and (8b) respectively. Since the consumption to income ratio coincides in both solutions, comparing (7c) and (10c) it becomes clear that the equilibrium labor supply (leisure) is inefficiently high (low) in the competitive solution.

Envious households consume above the socially desirable level. Given their budget constraint, this excess consumption can only be afforded at the expense of inefficient reductions in leisure. The presence of envy shifts the consumption-leisure tradeoff towards the former leading to inefficiently high levels of labor supply, capital accumulation and output.

In general the externality leads to a steady state distortion in the relevant variables which is a non-linear function of the equilibrium saving rate. In the simpler case where $\delta=n=g=0$, all steady state output is consumed and the following relation arises between the equilibrium values of the decentralized and centrally planned economies: $\frac{1-\tilde{l}^{d}}{1-\tilde{l}^{p}}=\frac{\tilde{k}^{d}}{\tilde{k}^{p}}=\frac{\tilde{c}^{d}}{\tilde{c}^{p}}=\frac{\theta /(1-\gamma)+\sigma}{\theta+\sigma}>1$. The distortion caused by envious behavior increases with the elasticity of output to capital, $(1-\sigma)$, and with the elasticity of utility to leisure, $\theta$. Increases 
in both elasticities increase the steady state level of leisure amplifying the misallocation of resources.

\section{Assessing the effects of the distortion}

In this section we calibrate our model to reproduce some of the key features of developed economies. Our goal is to quantify the importance of the distortions and welfare costs associated with envy. The rate of depreciation, $\delta=0.05$, the rate of population growth, $n=0.015$, and the rate of exogenous technological change, $g=0.02$, are conventional values and require no further explanation. We set the rate of time preference, $\beta=0.02$, and the parameter that governs the willingness to shift consumption across time, $\varepsilon=2$, so that the steady state saving rate is close to $25 \%$ and the steady state net return on capital is $5 \%$, both of them plausible long-run equilibrium values in closed economies with no public sector.

The remaining three parameters; $\sigma, \theta$ and $\gamma$, are the only ones that play a prominent role in our analysis. If factors are paid their marginal products and technology is Cobb-Douglas the elasticity of output with respect to labor, $\sigma$, coincides with the labor income share. Consistent with the evidence presented by Gollin (2002) we set this elasticity equal to .67.

The leisure parameter, $\theta$, governs the responsiveness of labor supply to changes in relative prices and the allocation of time between labor and leisure. In general, labor supply responds to changes in wages along two margins; the number of hours worked (intensive margin) and the decision to join the labor force (extensive margin). The micro-econometric evidence on labor supply elasticities along the intensive margin is abundant. Alesina et al. (2005) provide a summary of this literature concluding that the response of hours worked to changes in the real wage is relatively modest for men, with elasticities ranging from 0 to .84 . In contrast, Cho and 
Cooley (1994) model the participation decision generating elasticities as high as 4 when choices are limited to the extensive margin. Since we plan to contrast our model with data that combines both margins, hours worked and labor force participation, we choose a benchmark value of $\theta=1.7$, the standard figure used in the real business cycle literature; see Cooley and Prescott (1995). Along the stable growth path, our choice leads to an elasticity of labor supply ${ }^{5}$ below 2 and to a fraction of time devoted to leisure close to $66 \%$, consistent with the microeconomic evidence on time allocation provided by Juster and Stafford (1991). Since an agent has about 100 hours of productive time per week, the steady state workweek length is slightly above 34 hours.

Finally, direct evidence on the value of the envy parameter, $\gamma$, is sparse. The literature on the equity premium puzzle suggests values close to one; see Abel (1990), Gali (1994) and Campbell and Cochrane (1999). Easterlin (1995) and Frey and Stutzer (2002) evaluate the time series and cross-sectional properties of several measures of self-reported happiness. Their findings are consistent with preference specifications that place most of the weight on relative consumption. Alpizar et al. (2005) conduct several experiments to assess the importance of relative consumption. In the case of cars and housing their median estimate for $\gamma$ is between 0.5 and 0.75. Ravn, et al. (2006) report a point estimate of our envy parameter, where relative consumption is defined as a declining weighted average of past and present average consumption, of 0.86. Ravina (2005), using individual consumption data, estimates a weight of relative consumption close to one third. In view of these estimates, we choose a conservative value, $\gamma=0.5$, for the benchmark calibration and conduct extensive sensitivity analysis based on the range of reported estimates.

\footnotetext{
${ }^{5}$ As Glaeser et al. (2003) and Alesina et al. (2005) argue, elasticities in this range could be reconciled with microdata estimates in the presence of social multipliers that in our context arise naturally from status concerns.
} 
Table 1 summarizes the steady state values for the competitive and the efficient solutions, the size of the steady state distortion generated by envy and a measure of the welfare cost associated with it. In our benchmark calibration, $\gamma=0.5$, the competitive economy chooses a labor effort along the stable growth path close to 34 hours per week compared with the 21 hours chosen along the efficient solution. The presence of envy increases the private value of consumption above its social value leading to a steady state level of consumption that is $66 \%$ larger than the efficient one. Over-consumption could be sustained only at the expense of parallel increases in both inputs of production, and therefore the steady state levels of labor and capital exceed by two thirds the efficient levels. We measure the welfare cost as the percentage increase in individual (and average) consumption, today and in all future dates, that an agent living in the laissez-faire economy should receive in order to enjoy the same intertemporal welfare as an agent living in the centrally planned economy ${ }^{6}$. In our benchmark economy the potential welfare gains from eliminating the distortions created by envy are very high, equivalent to a $22.1 \%$ permanent increase in consumption.

The remaining columns in Table 1 explore the steady state effects of changes in the importance of comparative consumption. When preferences are independent, $\gamma=0$, the competitive solution is efficient and thus coincides with the planner's choice. As envy increases, the central planner realizes that the social gains from additional consumption are only a fraction $(1-\gamma)$ of the private gains and, as a result, he chooses lower levels of consumption and capital and higher levels of leisure. On the other hand, as envy increases so does the private marginal benefits of consumption and therefore competitive agents chose higher steady state levels of

\footnotetext{
${ }^{6}$ See the Appendix for a formal derivation.
} 
consumption and capital, reducing their leisure time ${ }^{7}$. Both responses reinforce each other leading to the steady state distortion presented in Table 1 that represents the percentage difference in consumption, capital and hours worked between the competitive and efficient solutions. As it is evident from the simpler case discussed in the previous section, when all steady state output is consumed, the distortion induced by the externality grows at an increasing rate with envy. If envy does not matter much, low values of $\gamma$, the implied distortions are small and more importantly the associated welfare losses are limited; as an example if $\gamma=0.2$, competitive agents consume and work around $17 \%$ in excess of the efficient level but their welfare loss is only $1.6 \%$. On the other hand as we move closer to the values of $\gamma$ suggested by the asset pricing, subjective happiness and experimental literatures the distortions and the associated welfare losses become huge; when $\gamma=0.8$ consumption, capital and hours of work under laissez-faire are almost four times larger than the efficient levels and we need to increase current and future consumption by a factor of 4.4 to compensate a competitive household for the negative impact of envy ${ }^{8}$.

A competitive economy populated by envious households reaches a steady state characterized by over-consumption, over-investment and over-working. Under these circumstances the government can restore efficiency by means of distortionary taxation. In general, any policy that increases the price of consumption relative to leisure, a tax on

\footnotetext{
${ }^{7}$ Under homothetic preferences increases in envy lead to identical behavioral responses in the competitive solution than decreases in the degree of curvature of the utility function in the consumption dimension, captured by the inverse of the intertemporal elasticity of substitution, $\eta \equiv \gamma(1-\varepsilon)+\varepsilon$.

${ }^{8}$ The distortions introduced by envy are not very sensitive to changes in the parameter governing the degree of curvature of utility, $\varepsilon$. In the other hand since the effects of envy on welfare are channeled through an inefficient increase in working hours, reductions on the importance of leisure in preferences, $\theta$, lead to reductions in the size, and welfare costs, of the distortion. In the limiting case where labor is inelastically supplied, $\theta=0$, envy does not distort the competitive allocation of resources.
} 
consumption or a subsidy on leisure, will move the economy closer to the efficient allocation ${ }^{9}$. Comparing the marginal rate of substitution between consumption and leisure for the centrally planned and decentralized solutions, the following relation for the optimal tax rates emerges:

$$
\frac{1-\tau_{w}}{1+\tau_{c}}=1-\frac{\tau_{c}+\tau_{w}}{1+\tau_{c}} \equiv 1-\tau=1-\gamma
$$

This result is consistent with the optimal fiscal policy derived under more general specifications of envy by Fischer and Hof (2000) and Liu and Turnovsky (2005). The last two rows of Table 1 present the implied tax rates that allow the decentralized equilibrium to mimic the results of the centrally planned economy. In our benchmark calibration, if labor is untaxed, consumption should be taxed at a rate of $100 \%$ to induce the first best outcome. Once the effects of the consumption externality have been taken care of, the optimal tax on capital income is zero, in line with the results of Chamley (1986) and Judd (1985).

\section{Envy, working hours, taxes and welfare in the G-7 countries}

There is considerable time series and cross-sectional variation in the average number of working hours among G-7 countries. According to the Groningen Growth and Development Centre, GGDC (2006), in 2005 an average French worker spent below 28 hours per week in the workplace as compared to the average Canadian worked almost 35 hours per week. These differences are even larger across time, in 1950 both French and Canadian workers spent close to 40 hours per week at work. This variation is summarized in Figure 1 which presents the evolution of working hours per week, total hours worked per week divided by average

\footnotetext{
${ }^{9}$ As opposed to Alonso-Carrera et al. (2006) where the externality leads to an inefficient transition through its effects on the willingness to substitute consumption through time, under our specification the externality only affects the evolution of key variables through its effects on the willingness to substitute consumption and leisure at any point in time. With the externality only distorting this static allocation, a constant tax rate will suffice to restore efficiency.
} 
employment, for both countries ${ }^{10}$. These important differences in the number of hours worked could arise as a consequence of different institutional environments, different constraints, or differences in tastes across countries and time. In the context of the model presented in the previous sections we explore to what extent the observed differences in the length of the workweek could be the response of envious households to differences in the after-tax prices of labor, consumption and capital.

Following Mendoza et al. (1994) and Prescott (2004), we compute effective tax rates on consumption, labor income and capital income combining revenue statistics data and modelspecific accounting relations. The resulting rates are consistent with the tax distortions faced by a representative household in each of the G-7 economies. The Organization for Economic Cooperation and Development Revenue Statistics, OECD (1999), provides data on revenues as a percentage of GDP for taxes on consumption, $T_{c}$, personal income, $T_{p i}$, corporate income, $T_{c i}$, social security, $T_{\mathrm{ss}}$, and payroll, $T_{p}$. Since nominal consumption expenditures in the national accounts are valued at post-tax prices, the relevant tax on consumption, $\tau_{c}$, satisfies the following relation,

$$
\tau_{c}=T_{c}\left(\frac{y+c \tau_{c}}{c}\right)
$$

where lower cases refer to our model-specific variables described in Section 2. Since the typical household files a single return for capital and labor income, revenue data on personal income taxes does not distinguish between these two sources of income. We follow Mendoza et al. (1994) by assuming that all sources of personal income are taxed as the same level, which

\footnotetext{
${ }^{10}$ The reader should be aware that estimates of working hours present serious cross-country comparability problems since the method of calculation varies from country to country.
} 
combined with our theoretical assumption that factors are paid their marginal product yields the following relations for the effective tax rates on labor income, $\tau_{w}$, and capital income $\tau_{k}$ :

$$
\tau_{w}=\left(\sigma T_{p i}+T_{s s}+T_{p}\right)\left(\frac{y+c \tau_{c}}{\sigma y}\right) \quad \tau_{k}=\left((1-\sigma) T_{p i}+T_{c i}\right)\left(\frac{y+c \tau_{c}}{(1-\sigma) y}\right)
$$

Since we calibrate our model under the assumption that the representative agent adjusts her labor-leisure choice along both the intensive and the extensive margins we need to construct a measure of labor supply that captures changes along both margins. The Key Indicators of the Labour Market published by the International Labor Organization, ILO (2005), provide data on labor force participation and annual hours worked per person employed. We can compute the measure of labor supply relevant for our model economy, hours worked per person between 15 and 64 years of age, as the product of those two data series.

Table 2 and Figure 2 compare the data on weekly hours worked per person aged 15 to 64 with its model counterpart, the hours worked by the representative agent living in our model economy in the face of tax distortions equivalent to the ones faced by households in the G-7 countries during 1998. The model is calibrated as the benchmark economy in the previous section. Despite the simplifying assumptions the model captures an important share of the variation in working hours in our sample. Differences in tax rates can amount for around one third of the variation in working hours observed in the data ${ }^{11}$. Figure 3 compares the evolution of actual and predicted hours worked for Canada and France from 1965 to 1995. It is surprising that a framework that abstracts from institutional differences, population structure and other factors

\footnotetext{
${ }^{11}$ As Alesina et al. (2005) point out, besides tax rates, there is a host of other variables such as strength of unions, extent of welfare coverage, and degree of income inequality that move together in our sample economies and that potentially influence the amount of hours worked. Their estimate of the elasticity of labor supply, derived from aggregate data, is able to explain around $36 \%$ of the difference in hours worked between France and the US and $34 \%$ between Italy and the US, very much in line with our numerical results.
} 
relevant for labor market outcomes is able to capture the basic features of the changes in labor supply that took place over the last decades of the past century.

We use this simple framework to investigate the potential welfare gains associated with the introduction of the optimal fiscal structure as defined in the previous section. In all our calculations we assume that each of the G-7 economies starts along the stable growth path consistent with the observed tax rates for 1998. First, we calculate the welfare gain associated with the complete elimination of capital income taxation, leaving labor income and consumption taxation at their 1998 levels. Second, we calculate the welfare gain associated with the introduction of the optimal fiscal package characterized in (11), leaving capital income taxation at the 1998 level. Third, we calculate the welfare gain associated with the optimal fiscal policy that combines the elimination of capital income taxation with the optimal mix of consumption and labor income taxation. Finally, we calculate the welfare gain associated with the complete elimination of the current tax schedules. The last four rows of Table 2 report these calculations.

For our benchmark calibration of envy, $\gamma=0.5$, countries with relatively low consumption and labor income taxes, Japan and the U.S., suffer a $1 \%$ welfare loss as a consequence of the elimination of capital taxation. On the other hand countries that begin with relatively high levels of taxation, France and Italy, do not benefit from additional increases in taxes, experiencing small welfare losses when the optimal value of (11) is implemented. In the former economies, a positive tax on capital income, through its depressing effects on investment and labor supply, improves welfare by reducing the distortions introduced by envy. These lowtax economies would experience substantial welfare gains, close to 3\%, after the introduction of the optimal mix of consumption and labor income taxes. In the latter economies the already high initial level of taxes reduces the scope for any benefit derived from additional increases in 
consumption or labor income taxes. These high-tax economies would experience important welfare gains, in the order of $1 \%$, after the elimination of the capital income tax. In general the benefits from implementing the optimal fiscal package are large, ranging from $4.5 \%$ for the U.S. to slightly below $1 \%$ for Germany.

Finally, the last row of Table 2 presents the welfare losses associated with setting all the taxes equal to zero. As we have already argued, substantial consumption and labor income taxes are required to prevent envious households from over-consuming, over-investing and overworking. Not surprisingly the elimination of the actual taxes is associated with welfare losses as high as $17 \%$ in the cases of Germany and France ${ }^{12}$.

\section{Envy and working time regulations.}

The reduction in working hours reported in the previous section is both a recent phenomenon and part of a secular trend ${ }^{13}$. Combining data from Huberman (2004) and ILO (2005), the estimated average yearly working hours per worker have declined from around 3,000 in 1870 to less than 1,700 in 2005 for our sample of economies. Apart from other institutional changes, the continuous tightening of working time regulations has played an important role in this reduction of working hours.

In 1870 average working time of a Canadian manufacturing worker was close to 65 hours per week. In 1889 the Royal Commission on the Relations of Labour and Capital promoted the 9-hour day for women and children but it was not until the 1920's and 1930's that maximumhour legislation covering adult male workers was adopted in some provinces. In 1922, the One

\footnotetext{
${ }^{12}$ In the era of globalization one might argue that envy is a transnational phenomenon. If a mixture of national and transnational comparisons matters, national policies that limit the amount of working hours might have ambiguous effects on welfare. Despite this most of the available evidence suggests that interpersonal comparisons are most important at a relatively local level.

${ }^{13}$ See Ramey and Francis (2006) for an alternative interpretation of the evolution of leisure over the $20^{\text {th }}$ Century in the US.
} 
Day's Rest in Seven Act provided for at least 24 consecutive hours rest per week. In 1968 Ontario introduced the Employment Standards Act limiting the amount of hours per week to a maximum of 48 hours.

The extent of government intervention is stronger in France. The 12-hour workday was introduced in 1841, and there was a 1848 attempt to reduce the maximum daily hours to 10 that was aborted a few months later. At the turn of the $20^{\text {th }}$ Century the Millerand Law reduced the workday to 11 hours in 1902 and 10 hours in 1904. In 1936 the left-wing coalition that formed the Popular Front introduced the 40-hour week. In 1986 a regulation reducing the workweek to 39 hours was approved and in 1998, under Prime Minister Lionel Jospin, the Aubry Law initiated the move towards the 35-hour workweek ${ }^{14}$.

An additional limitation to working hours takes the form of statutory vacation time. Alesina et al. (2005) decompose the differences in working hours per person for the US, France and Germany into differences in the number of days of vacation and differences in the number of hours worked in a standard week. They find that roughly one quarter of the total differences in hours worked is explained by differences in the standard week while almost one third is explained by differences in mandated holidays.

The traditional arguments in support of working time regulations appeal to their beneficial effects on the living standards of workers. In contrast, the recent debate that accompanied the approval of the Aubry Law in France has shifted these arguments towards employment creation and work-sharing. Marimon and Zilibotti (2000) explore the employment effects of workweek regulations in a general equilibrium search-matching model with fixed hiring costs and endogenous wage adjustment. Their quantitative results suggest that if reductions in the workweek have positive effects on employment, these effects are almost

\footnotetext{
${ }^{14}$ Data for France is from Marchand and Thelot (1991) and for Canada is from Woods and Ostry (1962).
} 
negligible. These results are consistent with the empirical evidence evaluated in Hunt (1998).

Nevertheless, despite the ambiguous effects in terms of job creation, if envy is an important feature of human behavior, workweek regulations can play an important role by limiting the distortions introduced by envious consumption ${ }^{15}$. In a context where the optimal fiscal package described in (11) is not politically feasible ${ }^{16}$, policies that enjoy broader popular support, such as workweek limitations or mandatory vacation time, could be an alternative instrument for the government to induce a market outcome closer to the social optimum. We modify the framework presented in section 2 to introduce working time limitations in the form of an additional constraint,

$$
l_{i}(t) \geq \tilde{l}^{p}
$$

that requires the representative agent to choose a level of leisure at any point in time at least as high as the steady state level of leisure chosen by the central planner. Assuming taxes are equal to zero and denoting by $\mu_{i}$ the Lagrange multiplier associated with (12), the optimality conditions for this program are identical to (4) except for (4b) which is replaced by

$$
\theta\left(C_{i}^{r}\right)^{1-\varepsilon}\left(\bar{C}^{r}\right)^{-\gamma(1-\varepsilon)}\left(l_{i}^{r}\right)^{\theta(1-\varepsilon)-1}+\mu_{i}=\lambda_{i}^{r} w^{r}
$$

with $\mu_{i} \geq 0, \quad l_{i}^{r}-\tilde{l}^{p} \geq 0, \quad \mu_{i}\left(l_{i}^{r}-\tilde{l}^{p}\right)=0$.

where the superscript " $r$ " denotes choices under regulations on working hours. If the working time limitation is not binding, $\mu_{i}=0$, (13) reduces to (4b) and the dynamic behavior of this

\footnotetext{
${ }^{15}$ Along these lines Alesina et al. (2005) find a negative relationship between hours worked and life satisfaction across European countries. This relation is robust to the introduction of country and year fixed effects and the use of collective bargaining agreements as an instrument for hours worked.

${ }^{16}$ For our benchmark calibration of envy, $\gamma=0.5$, the optimal tax on consumption is $100 \%$ when the tax on labor income is set to 0 , and the optimal tax on labor income is $50 \%$ when the tax on consumption is set to 0 . Less conservative values of the externality, for instance $\gamma=0.8$, require a tax on labor income of $80 \%$ when the tax on consumption is set to 0 , and a tax on consumption of $400 \%$ in the absence of labor income taxation.
} 
economy is fully characterized by (7). In the face of our previous quantification of the leisure choices under laissez faire, a more interesting scenario is one in which the workweek limitation is binding at any point in time. In this case, $l_{i}^{r}=\tilde{l}^{p}$ and this economy reduces to a neoclassical growth model with exogenous labor with its equilibrium dynamics being described by the following pair of differential equations,

$$
\begin{aligned}
& \dot{k}^{r}=\alpha\left(1-\tilde{l}^{p}\right)^{\sigma}\left(k^{r}\right)^{1-\sigma}-(\delta+n+g) k^{r}-c^{r} \\
& \dot{c}^{r}=\frac{c^{r}}{\eta}\left(\alpha(1-\sigma)\left(\frac{1-\tilde{l}^{p}}{k^{r}}\right)^{\sigma}-\beta-\delta-n-\eta g\right)
\end{aligned}
$$

together with the initial condition, $k^{r}(0)=k_{0}$, and the transversality condition (4d). If the constraint is binding along a stable growth path, $\dot{k}^{r}=\dot{c}^{r}=0$, it is easily shown that the levels of capital and consumption chosen by competitive agents are identical to the efficient levels chosen by a central planner.

We can use this framework to compare the adjustment of the economy under two alternative policy arrangements; the optimal fiscal policy that induces the decentralized economy to mimic the behavior of the centrally planned economy and working time regulations that impose at least the same level of leisure that a central planner would choose in steady state. Figure 4 summarizes the dynamic adjustment of the key economic variables, expressed as percentage deviations from their initial steady states, after the two policies are implemented. In both cases we assume that the economy begins along the laissez-faire steady state. Along the initial steady state consumption, capital and labor supply exceed their efficient levels by two thirds. Once the optimal fiscal policy is in place, the increase in the after tax relative price of consumption with respect to leisure leads to an immediate decrease in consumption (Panel b) and 
an increase in leisure (Panel c). With capital and labor being complementary in production, the decrease in labor supply reduces the average product of capital below its replacement rate and, despite the decrease in consumption, capital begins to fall (Panel d). This process of disinvestment leads to further decreases in output and consumption that are only partially compensated by a continuous increase in the number of hours worked induced by the income effect. The remaining adjustment is characterized by monotonic decreases in capital, leisure, output and consumption until the new steady state is reached.

The adjustment of the constrained economy is qualitatively similar to the efficient adjustment, with the key difference arising from the fact that the optimal fiscal policy allows agents to adjust along two margins, consumption and leisure, while the reduction in the workweek only allows the representative agent to adjust along the consumption-saving tradeoff. When the government imposes the working time restriction, relative prices are not directly affected, and nor is the willingness of the agent to over-work and over-consume. Given the constraint the agent reduces her working hours to the highest feasible level, which at the initial stage of the transition exceeds by $12 \%$ the level chosen under the optimal fiscal package. Since the capital stock is fixed, the decrease in working hours leads to an immediate decrease in output and consumption. The decrease in consumption, which is only a fraction of the decrease under the optimal tax policy, cannot sustain the initial level of capital so capital begins to decumulate. The unsustainably high, but decreasing, level of consumption leads to a transition characterized by monotonic decreases in capital and output.

Panel e) compares the evolution of instantaneous welfare, defined as the percentage increase in individual (and average) consumption in period $t$ that an agent living in the laissezfaire economy should receive in order to enjoy the same welfare in period $t$ as an agent living 
under each of the policy arrangements considered. In the initial stage of the transition the relatively low level of leisure under workweek regulations leads to a welfare loss, relative to the optimal fiscal package, which is partially compensated by the higher level of consumption achieved. After a decade, this relative loss is reversed when the reduction in welfare caused by over-working is more than compensated by the higher feasible consumption level. The intertemporal welfare gain associated with the optimal fiscal policy is $22.1 \%$, only $0.05 \%$ larger than the welfare gain under workweek regulations. Our analysis suggests that, in circumstances where the optimal fiscal policy is difficult to implement, workweek regulations or legally mandated vacation time can achieve the efficient steady state allocation incurring in a surprisingly small welfare loss relative to the optimal course of action.

\section{Conclusions}

We have presented a simple model of capital accumulation where preferences are defined over leisure, and absolute and relative consumption. Our specification captures the intuition that lies behind the growing body of empirical evidence that places interpersonal comparisons as a key determinant of well-being. Envious households ignore the negative effects that their consumption choices impose on the welfare of their neighbors; as a result they consume, work and accumulate capital above welfare maximizing levels. Since envy increases the willingness to substitute from leisure towards consumption a tax policy that increases the price of consumption relative to leisure is enough to induce the market economy to replicate the first best outcome.

We use this framework to explore the size of the distortions introduced by envy. Our numerical results suggest that the welfare losses associated with envy are very large. In our benchmark calibration the welfare gain associated with the implementation of the optimal fiscal 
policy is equivalent to a permanent increase in consumption close to one fourth of the laissez faire level of consumption.

We compare the implications of our model for labor supply with cross-sectional and time series variation in working hours for the G-7 economies. We find that our simple framework is able to capture some of the basic features of the changes in labor supply through time and space. Under conservative estimates of the importance of envy, we evaluate the welfare gains associated with the introduction of the optimal fiscal policy in this group of developed economies. Our results suggest these gains are substantial, ranging from $4.5 \%$ for the U.S. to $1 \%$ to Germany. Furthermore, the welfare losses associated with the elimination of the present tax schemes are as large as $18 \%$ for Germany or France.

Finally we turn our attention to an alternative policy instrument that might work as a coordination device in the presence of consumption externalities; restrictions on working hours. If the increases in taxes associated with the implementation of the optimal fiscal package are politically costly, our results suggest that workweek limitations or mandated vacation time provide the policy maker an additional tool to move the market outcome closer to the efficient one. In view of these results it is possible that the French politicians that promoted the Aubry Law are like Friedman's (1953) billiard players, they know what to do but they cannot explain why they do it. 


\section{Figures and Tables}
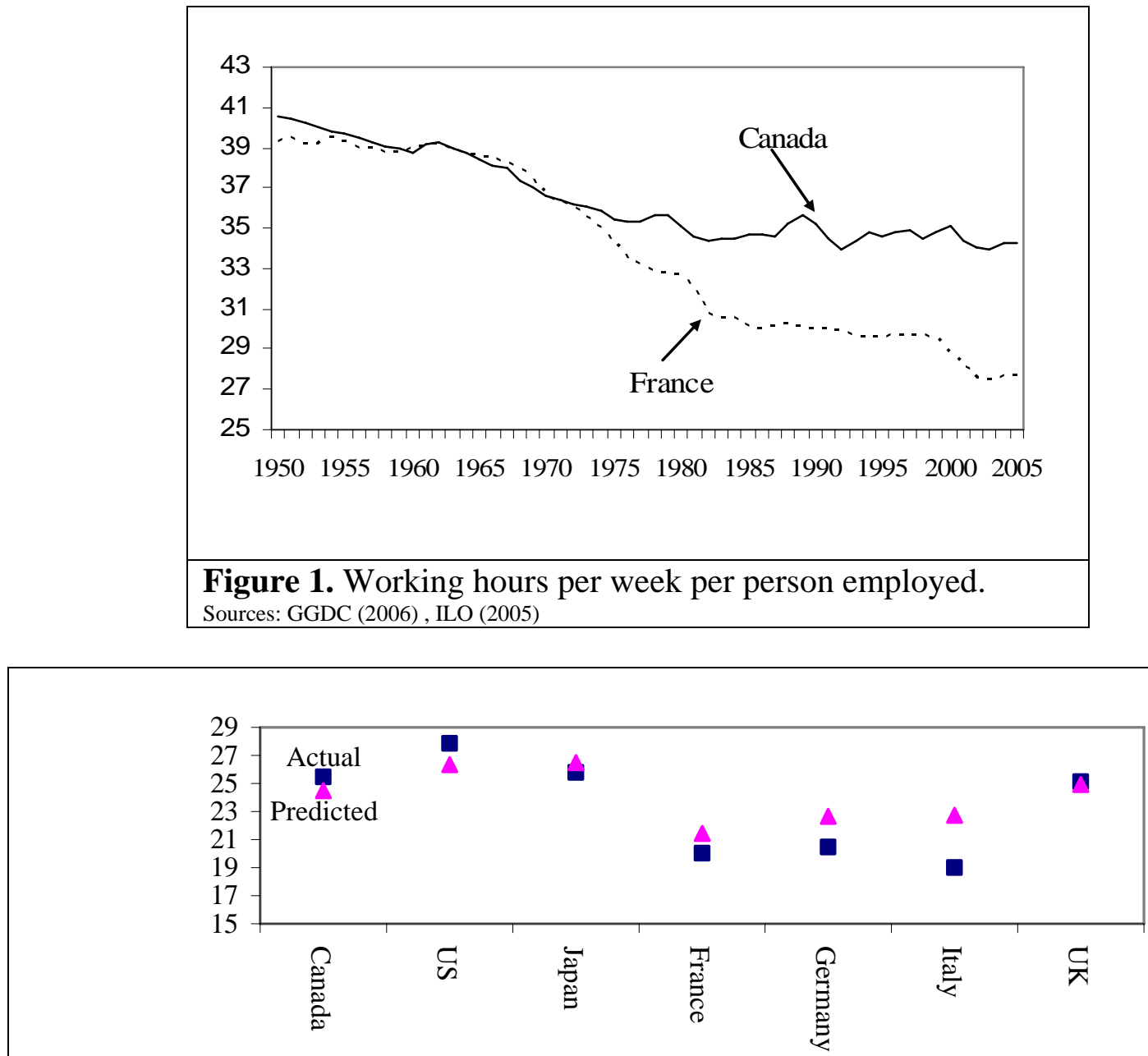

Figure 2. Working hours per week per person for 1998 between 15 and 65 years of age; model vs. data.

Sources: ILO (2005), OECD (1999)

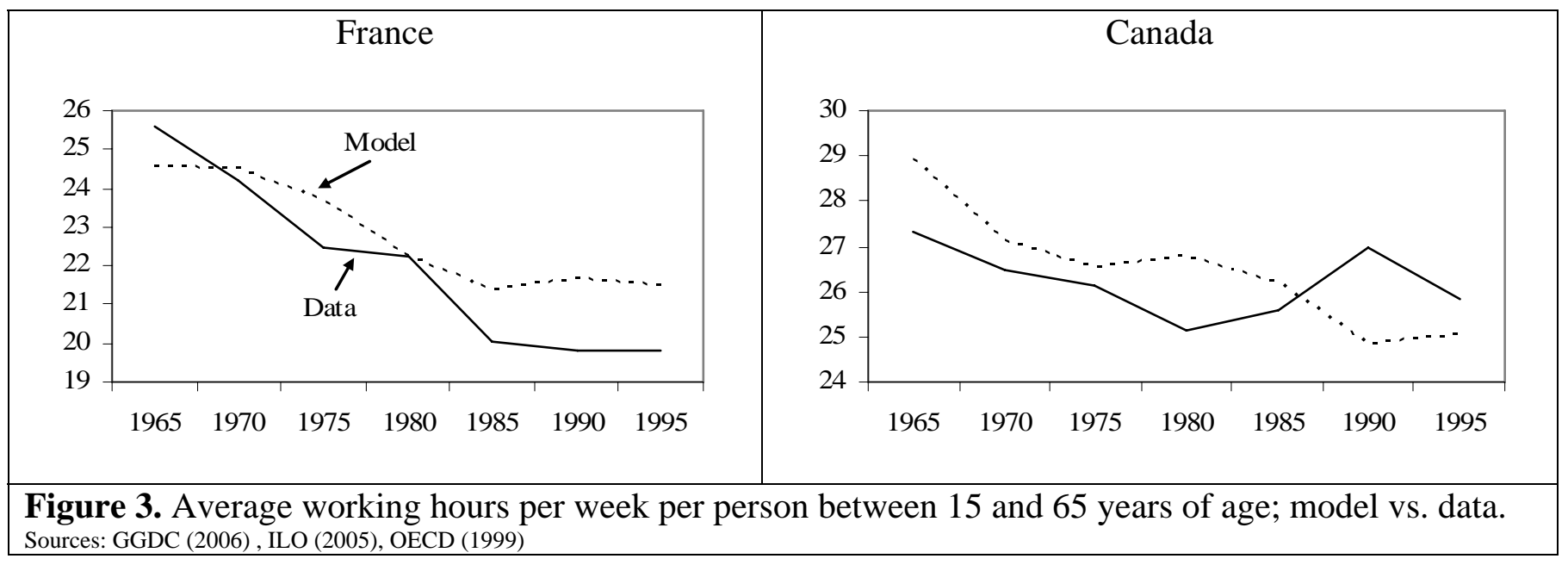




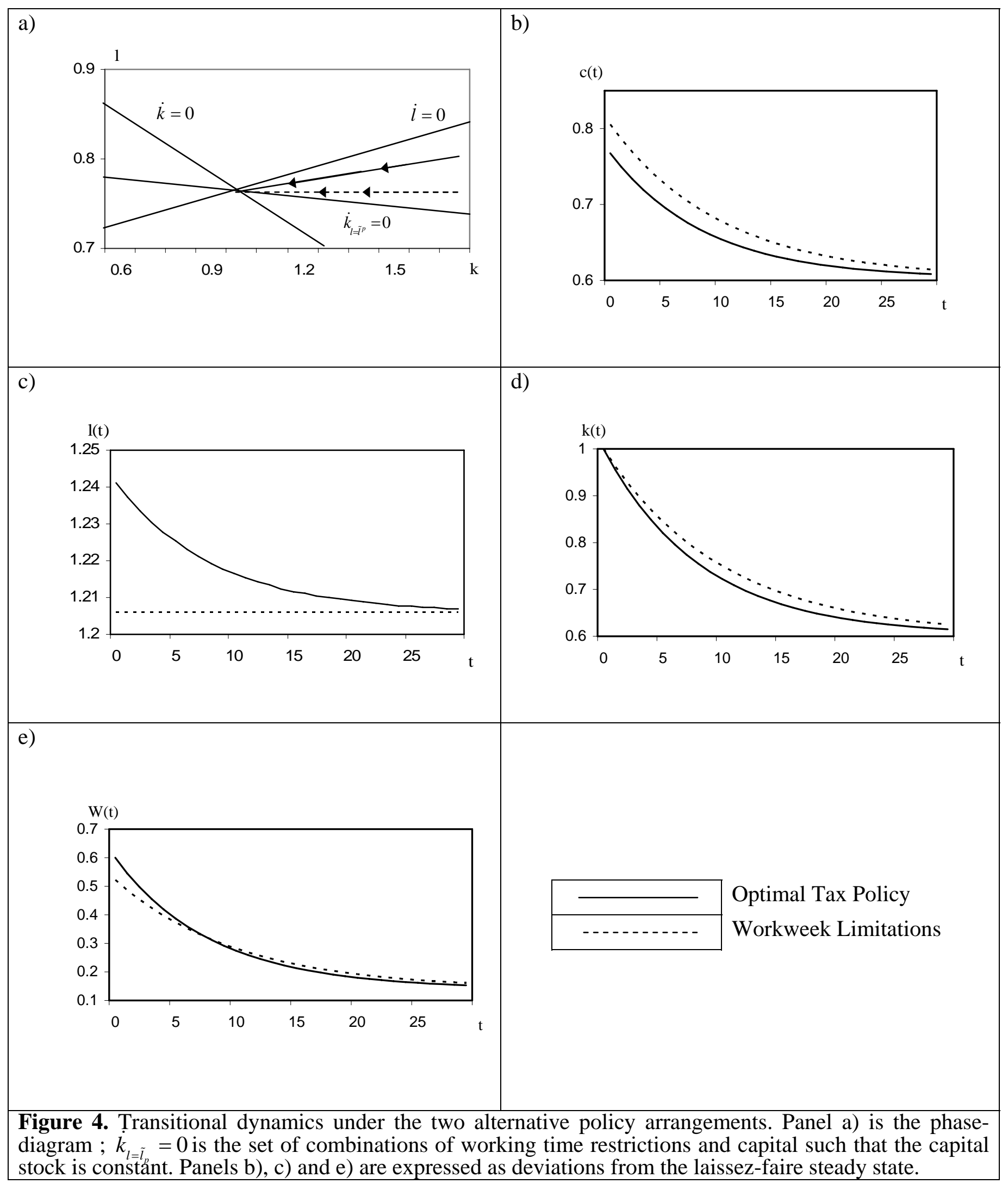




\begin{tabular}{|l|c|c|c|c|c|c|}
\hline & $\gamma=0$ & $\gamma=0.2$ & $\gamma=0.4$ & $\gamma=0.5$ & $\gamma=0.6$ & $\gamma=0.8$ \\
\hline Saving rate & $23 \%$ & $23.8 \%$ & $24.7 \%$ & $\mathbf{2 5 \%}$ & $25.5 \%$ & $26.5 \%$ \\
\hline$K / Y$ & 2.7 & 2.8 & 2.9 & $\mathbf{2 . 9 5}$ & 3 & 3.1 \\
\hline Interest rate & $6 \%$ & $5.6 \%$ & $5.2 \%$ & $\mathbf{5 \%}$ & $4.8 \%$ & $4.4 \%$ \\
\hline Growth rate & \multicolumn{5}{|c|}{$\mathbf{2 \%}$} \\
\hline Market hours/week & 33.5 & 33.8 & 34 & $\mathbf{3 4 . 1}$ & 34.3 & 34.5 \\
\hline Efficient hours/week & 33.5 & 29 & 23.6 & $\mathbf{2 0 . 6}$ & 17.3 & 9.6 \\
\hline Steady state distortion & $0 \%$ & $17 \%$ & $43 \%$ & $\mathbf{6 6 \%}$ & $98 \%$ & $261 \%$ \\
\hline Welfare cost & $0 \%$ & $1.6 \%$ & $10.5 \%$ & $\mathbf{2 2 . 1 \%}$ & $47.5 \%$ & $439 \%$ \\
\hline$\tau_{c}^{\text {opt }}$ when $\tau_{w}=0$ & $0 \%$ & $33 \%$ & $66 \%$ & $\mathbf{1 0 0 \%}$ & $150 \%$ & $400 \%$ \\
\hline$\tau_{w}^{\text {opt }}$ when $\tau_{c}=0$ & $0 \%$ & $25 \%$ & $40 \%$ & $\mathbf{5 0 \%}$ & $60 \%$ & $80 \%$ \\
\hline
\end{tabular}

\begin{tabular}{|c|c|c|c|c|c|c|c|}
\hline & Canada & US & Japan & France & Germany & Italy & UK \\
\hline Actual $\tau_{c}$ & $12.1 \%$ & $5.7 \%$ & $6.5 \%$ & $16.3 \%$ & $13.5 \%$ & $14.5 \%$ & $16 \%$ \\
\hline Actual $\tau_{w}$ & $25.1 \%$ & $24.1 \%$ & $23.7 \%$ & $37.1 \%$ & $34.6 \%$ & $32.4 \%$ & $21.8 \%$ \\
\hline Actual $\tau_{k}$ & $26.7 \%$ & $20.7 \%$ & $17.7 \%$ & $16.9 \%$ & $14.9 \%$ & $20.9 \%$ & $23.9 \%$ \\
\hline Actual hours per worker & 33.9 & 36 & 35.5 & 29.7 & 28.6 & 32 & 33.2 \\
\hline Participation rate & $75 \%$ & $77.4 \%$ & $72.6 \%$ & $67.4 \%$ & $71.4 \%$ & $59.2 \%$ & $75.7 \%$ \\
\hline Actual hours per person & 25.4 & 27.8 & 25.8 & 20 & 20.5 & 18.9 & 25.1 \\
\hline Predicted Hours & 24.5 & 26.4 & 26.5 & 21.4 & 22.6 & 22.7 & 24.9 \\
\hline Deviation (in hours) & 0.9 & 1.5 & -0.7 & -1.4 & -2.2 & -3.7 & 0.2 \\
\hline Welfare gain $\tau_{k}=0$ & $0.72 \%$ & $-0.6 \%$ & $-0.76 \%$ & $0.8 \%$ & $0.3 \%$ & $1.2 \%$ & $0.2 \%$ \\
\hline Welfare gain $\left(\tau_{c}+\tau_{w}\right) /\left(1+\tau_{c}\right)=\gamma$ & $0.9 \%$ & $2.8 \%$ & $3.1 \%$ & $-0.2 \%$ & $0.1 \%$ & $-0.01 \%$ & $1.24 \%$ \\
\hline Total Welfare gain & $3.86 \%$ & $4.5 \%$ & $4.3 \%$ & $1 \%$ & $1 \%$ & $1.8 \%$ & $3.6 \%$ \\
\hline Welfare gain $\tau_{k}=\tau_{w}=\tau_{c}=0$ & $-14.4 \%$ & $-14 \%$ & $-14.3 \%$ & $-16.8 \%$ & $-16.9 \%$ & $-16.1 \%$ & $-14.7 \%$ \\
\hline
\end{tabular}

Table 2. Actual and predicted hours worked for G-7 countries for 1998. Potential welfare gains.

Sources: ILO (2005), OECD (1999) 


\section{Appendix}

\section{Derivation of the system of differential equations for Section 2.1}

Log-differentiating (4a) and combining the result with (4c) and (6) we obtain,

$$
-[\varepsilon+\gamma(1-\varepsilon)] \hat{C}_{i}+(1-\varepsilon) \theta \hat{l}=\beta+\delta+n-\left(1-\tau_{K}\right)(1-\sigma) \frac{Y}{K}
$$

Log-differentiating (2) and (7c) where we use the fact that $\frac{C}{y}=\frac{C}{Y}$ we reach,

$$
\begin{aligned}
& \hat{Y}=\sigma\left(g+n-\frac{i}{1-l}\right)+(1-\sigma) \hat{K} \\
& \hat{C}_{i}=\hat{Y}+\frac{i}{l(1-l)}-n
\end{aligned}
$$

Finally the aggregated budget constraint implies that,

$$
\hat{K}=\frac{Y}{K}-\delta-\frac{C}{K}
$$

Combining these four equations we find equations (7b). Equation (7a) results from expressing (A.4) in units of effective labor.

The dynamics of (7) can be approximated by the following second-order system, where without loss of generality we set $\tau_{K}=0$ :

$$
\left.\left(\begin{array}{l}
\dot{k} \\
\dot{l}
\end{array}\right)=\left(\begin{array}{cc}
-\sigma(\delta+g+n) & -\left[\frac{c / y}{l}+\left(1-\frac{c}{y}\right) \sigma\right] \frac{y}{(1-l)} \\
-F(l)\left[1-\eta\left(1-\frac{c}{y}\right)\right](1-\sigma) \alpha \sigma \frac{y}{k^{2}} & F(l) \frac{(1-\sigma) y}{k(1-l)}\left[\eta \frac{c / y}{l}-\sigma+\eta\left(1-\frac{c}{y}\right) \sigma\right.
\end{array}\right]\right)_{\substack{k=\tilde{k} \\
l=\tilde{l}}}\left(\begin{array}{l}
k-\tilde{k} \\
l-\tilde{l}
\end{array}\right)
$$


That under mild conditions, for instance $\eta s^{s s}<1$ where $s^{s s}$ is the steady state saving rate, exhibits saddle path stability. All the simulations presented in the text are based on the previous linear approximation.

\section{Welfare analysis}

We assume that the economy is initially on a balanced growth path consistent with the competitive solution. Normalizing the initial level of technology to one, so that at time 0 variables per capita and variables per unit of effective labor coincide, the corresponding level of base welfare is given by:

$$
W_{d}\left(c_{d}, l_{d}\right) \equiv \frac{1}{1-\varepsilon} \int_{0}^{\infty}\left(C_{i, d} \bar{C}_{i, d}^{-\gamma} l_{i, d}^{\theta}\right)^{1-\varepsilon} e^{-\beta t} d t=\frac{\left(c_{d}\right)^{(1-\gamma)(1-\varepsilon)} l_{d}^{\theta(1-\varepsilon)}}{1-[(1-\varepsilon)(1-\gamma) g-\beta]}
$$

Now consider the equilibrium transitional path from the competitive allocation of resources to the efficient allocation chosen by a central planner. The level of welfare along such a path is given by,

$$
W_{p}\left(c_{p}, l_{p}\right) \equiv \frac{1}{1-\varepsilon} \int_{0}^{\infty}\left(C_{i, p}^{1-\gamma} l_{i, p}^{\theta}\right)^{1-\varepsilon} e^{-\beta t} d t=\frac{1}{1-\varepsilon} \int_{0}^{\infty}\left(\left(c_{p}(t)\right)^{1-\gamma}\left(l_{p}(t)\right)^{\theta}\right)^{1-\varepsilon} e^{[(1-\varepsilon)(1-\gamma) g-\beta] t} d t
$$

Where $c_{p}(t)$ and $l_{p}(t)$ denote the time-varying trajectories from the competitive stable growth path to the centrally planned one.

As means of comparing these two levels of utility, we determine the percentage change in the consumption (individual and average) flow over the entire base path such that an agent is indifferent between $c_{d}, l_{d}$ and $c_{p}, l_{p}$. That is, we seek to find $\zeta$ such that,

$$
W_{d}\left(\zeta c_{d}, l_{d}\right)=W_{p}\left(c_{p}, l_{p}\right)
$$


So $(\zeta-1) * 100=\left(\left(\frac{W_{p}}{W_{d}}\right)^{\frac{1}{(1-\gamma)(1-\varepsilon)}}-1\right) * 100$ is the value reported as our measure of welfare change in Tables 1 and 2.

The instantaneous welfare gain presented in Figure 4e) is calculated equivalently but instead of considering the intertemporal welfare value we consider the level of welfare at each point in time. 


\section{References}

Abel, A. (1990). “Asset Prices Under Habit Formation and Catching Up With the Joneses,” American Economic Review 80, 38-42.

Akerlof, G. and J. Yellen (1990). “The Fair Wage-Effort Hypothesis and Unemployment.” The Quarterly Journal of Economics, 105, 2, 255-283

Alesina, A., E. Glaeser and B. Sacerdote (2005). "Work and leisure in the US and Europe: Why so different?” forthcoming in the NBER Macroeconomic Annual.

Alonso-Carrera J., J. Caballé, and X. Raurich (2005). "Growth, habit formation and catching-up with the Joneses." European Economic Review 49 (6). pp. 1665-1691, 2005.

Alonso-Carrera J., J. Caballé, and X. Raurich (2006). "Welfare implications of the interaction between habits and consumption externalities." forthcoming in International Economic Review.

Alpizar, F., F. Carlsson and O. Johansson-Stenman (2005). "How much do we care about absolute versus relative income and consumption?.” Journal of Economic Behavior and Organization, 56, 405-421.

Altonji, J.G. (1986). "Intertemporal Substitution in Labor Supply: Evidence from Micro Data.” Journal of Political Economy, 91, 3, 176-215.

Alvarez-Cuadrado, F., G. Monteiro and S.J. Turnovsky (2004). "Habit Formation, Catching up with the Joneses, and Economic Growth”, Journal of Economic Growth, 9, 47-80.

Alvarez-Cuadrado, F. and D. Sutthiphisal (2006). "Envy and Consumption Behavior: A panel data approach” McGill University Working Paper.

Argyle, M. (1989), The Psycology of Happiness. London: Routledge.

Aristotle, 1941, The Basic Works of Aristotle, R. McKeon (ed.), New York: Random House.

Blundell R. and T. MaCurdy (1999). "Labour Supply: A Review of Alternative Approaches” The Institute For Fiscal Studies Working Papers No. W98/18.

Cantril, H. (1965). The Pattern of Human Concerns. New Brunswick: Rutgers University Press.

Campbell, J.Y. and J.H. Cochrane (1999). "By Force of Habit: A Consumption-Based Explanation of Aggregate Stock Market Behavior,” Journal of Political Economy 107, 205-251.

Carroll, C.D., J.R. Overland, and D.N. Weil (1997). "Comparison Utility in a Growth Model”, Journal of Economic Growth 2, 339-367.

Chamley, C. (1986). "Optimal taxation of capital income in general equilibrium with infinite lives.” Econometrica, 54, 607-622

Cho, J. and T.F. Cooley (1994). "Employment and hours over the business cycle." Journal of Economic Dynamics and Control, 18, 411-432

Clark, A.E. and A.J. Oswald (1996). "Satisfaction and comparison income.” Journal of Public Economics, 61, 359-381

Cooley and Prescott (1995). "Economic Growth and Business Cycles” in Frontiers of business cycle research, Cooley, T.F. Ed. Princeton University Press. Princeton.

Dupor, B. and W-F. Liu (2003). "Jealousy and equilibrium overconsumption." American Economic Review, 93, 423-428

Dusenberry, J.S. (1949), Income, Saving and the Theory of Consumer Behavior, Harvard University Press, Cambridge, Mass.

Easterlin, R.A. (1995). “Will raising the incomes of all increase the happiness of all?” Journal of Economic Behavior and Organization, 27, 35-47 
Eaton, B.C. and M. Eswaran (2003). “The evolution of preferences and competition: a rationalization of Veblen's theory of invidious consumption” Canadian Economic Review, 36, 832-59.

Fisher, W. and F. Hof (2000). "Relative Consumption and Endogenous Labour Supply in the Ramsey Model: Do Status-Conscious People Work Too Much?” Institute for Advance Studies, Vienna.

Frank, R.H. (1985). Choosing the Right Pond, New York and Oxford: Oxford University Press.

Frey, B.S. and A. Stutzer (2002). "What Can Economists Learn from Happiness Research?," Journal of Economic Literature, 40, 402-435.

Friedman, M. (1953). Essays in Positive Economics, Chicago: University of Chicago Press.

Gali, J. (1994). "Keeping Up with the Joneses: Consumption Externalities, Portfolio Choice, and Asset Prices,” Journal of Money, Credit, and Banking 26, 1-8.

Glaeser, E., B. Sacerdote and J. Scheinkman (2003). “The Social Multiplier” Journal of the European Economic Association, 1, 2, 345-353

Gollin, D., (2002). “Getting Income Shares Right.” Journal of Political Economy, 110, 458-474.

GGDC (2006). "The Conference Board and Groningen Growth and Development Centre, Total Economy Database, May 2006.

Heckman, J.J. and T.E. MaCurdy (1980). “A life-cycle model of female labour supply.” Review of Economic Studies, 47, 47-74.

Helliwell, J. (2003). "How's Life? Combining Individual and National Variables to Explain Subjective Well-Being” Economic Modelling, 20, 2, 331-60

Huberman, M. (2004). "Working hours of the world unite? New international evidence of worktime, 1870-1913” Journal of Economic History, 64, 964-1001.

Hunt, J. (1998). "Hours Reductions as Work-Sharing.” Brooking Papers on Economic Activity, 1, 339-369.

ILO (2005). "Key Indicators of the Labour Market.” $4^{\text {th }}$ Edition. CD version.

Johansson-Stenman, O., Carlsson, F and D. Daruvala (2002). "Measuring future grandparents' preferences for equality and relative standing.” Economic Journal 112, 362-383

Judd, K. (1985). “The Welfare Cost of Factor Taxation in a Perfect Foresight Model.” Journal of Political Economy, 95

Juster, F.T. and F.P. Stafford (1991). "The Allocation of Time: Empirical Findings, Behavioral Models, and Problems of Measurement.” Journal of Economic Literature, 39, 471-522

Kant, I., (1797). "The Metaphysics of Morals," in The Cambridge Edition of the Works of Immanuel Kant: Practical Philosophy, Gregor, M. (ed. and trans.), New York: Cambridge University Press

Kapteyn, A., S. Van de Geer, H. Van de Stadt and T. Wansbeek (1997). "Interdependent Preferences: An Econometric Analysis” Journal of Applied Econometrics, 12, 6, 665686.

Layard, R. (2005). Happiness: lessons from a new science, New York: Penguin Press.

Liu, W-F and S.J. Turnovsky (2005). "Consumption externalities, production externalities, and long-run macroeconomic efficiency.” Journal of Public Economics, 89, 1097-1129

Luttmer, E. (2005). "Neighbors as Negatives: Relative Earnings and Well-Being." Quarterly Journal of Economics, 120(3), 963-1002.

Marchand, O. and C. Thelot (1991). Deux Siecles de travail en France. Paris: INSEE.

Marimon, R. and F. Zilibotti (2000). "Employment and distributional effects of restricting working time.” European Economic Review, 44, 1291-1326 
Mendoza, E.G., Razin, A. and L.L. Tesar (1994). "Effective tax rates in macroeconomics. Crosscountry estimates of tax rates on factor incomes and consumption.” Journal of Monetary Economics, 34, 297-323

Neumark, D. and A. Postlewaite (1998). "Relative income concerns and the rise in married women's employment.” Journal of Public Economics, 70. 157-183

OECD (1999). “Revenue Statistics 1965-1998.” Paris, 1998.

Pollak, R.A. (1976). "Interdependent Preferences” American Economic Review, 66, 3, 309-320

Prescott, E. (2004). "Why Do Americans Work So Much More Than Europeans?.” Federal Reserve Bank of Minneapolis Quarterly Review, 28, 2-13

Ravina, E. (2005). “Keeping Up with the Joneses: Evidence from Micro Data.” New York University Stern School of Business Working Paper.

Ravn, M., Schmitt-Grohe, S. and M. Uribe (2006). “Deep habits.” Review of Economic Studies, 73, 195-218

Rawls, J. (1971). A Theory of Justice, Cambridge, MA: Belknap Press.

Schoeck, H. (1966). Envy: A Theory of Social Behavior, Glenny and Ross (trans.), New York:

Harcourt, Brace.

Smith, A. (1759). The Theory of Moral Sentiments, Oxford: Clarendon Press.

Solnick, S. and D. Hemenway (1998). "Is more always better? A survey on positional concerns." Journal of Economic Behavior and Organization 37, 373-383

Turnovsky, S.J. and G. Monteiro (2006). "Consumption Externalities, Production Externalities and efficient capital accumulation under time non-separable preferences” forthcoming in European Economic Review.

Van de Stadt, H., A. Kapteyn, and S. van de Geer (1985). "The Relativity of Utility: Evidence from Panel Data,” Review of Economics and Statistics 67, 179-187.

Ramey, V and N. Francis (2006). "A Century of Work and Leisure”. Unpublished manuscript.

Veblen, T.B. (1899). The Theory of the Leisure Class: An Economic Study of Institutions, Modern Library, New York.

Woods, H.D. and S. Ostry (1962). Labour Policy and Labour Economics in Canada, MacMillan fo Canada, Toronto. 